\title{
Narrar uma tragédia do presente: transgressões ao regime das práticas em Todo dia a mesma noite, de Daniela Arbex ${ }^{1}$
}

\author{
Marlon Santa Maria Dias \\ https://orcid.org/0000-0002-0175-9217
}

I - Unisinos

São Leopoldo (RS). Brasil

Resumo: O artigo examina passagens do livro Todo dia a mesma noite, de Daniela Arbex, e entrevistas concedidas pela jornalista sobre o processo de apuração e escrita da reportagem sobre a "Tragédia de Santa Maria". Objetiva-se perceber as aproximações do trabalho de Arbex à noção de "livro de repórter", sinalizando a potencialidade crítica dessa escrita como um processo transgressivo de reconhecimento do presente. Como chave de leitura, utiliza-se a noção de "evento crítico", a fim de compreender as particularidades dessa crítica quando o sofrimento é um operador significante na construção narrativa do acontecimento.

Palavras-chave: livro de repórter; transgressão; tragédia; narrativa.

Abstract: Narrating a tragedy of the present: transgressions against the regime of practices in Daniela Arbex's book Todo dia a mesma noite - The paper examines excerpts from Daniela Arbex's book Todo dia a mesma noite (Everyday the same Night) and interviews given by the journalist about the process of investigating and writing the report on the Tragedy of Santa Maria. The purpose of the study is to understand the consonance of Arbex's work with the notion of "books written by reporters," signaling the critical potential of this writing as part of a transgressive recognition of the present. Moreover, the notion of "critical event" is a reading key in order to understand its particularities when suffering is a significant operator in the narrative construction of the event.

Keywords: books written by reporters; transgression; tragedy; narrative.

1 O presente trabalho foi realizado com apoio da Coordenação de Aperfeiçoamento de Pessoal de Nível Superior - Brasil (CAPES) - Código de Financiamento 001. 
Na manhã de 27 de janeiro de 2013, os moradores de Santa Maria (RS) foram acordados com a notícia do incêndio na Boate Kiss, que vitimou 242 pessoas. O evento ganhou materialidade discursiva quando uma das jovens que estava na festa publicou um pedido de socorro em seu perfil no Facebook, conectando o acontecimento ao mundo exterior. Ainda na madrugada, sem ter noção da dimensão da tragédia, repórteres dos veículos de comunicação da cidade se deslocaram para frente da boate. Juliana Motta (2016, p. 15), à época repórter da RBSTV, relata o caos: "Muita fumaça, jovens desacordados, pessoas sendo reanimadas nas calçadas, o vaivém de ambulâncias, o desespero de voluntários e bombeiros que tentavam retirar do prédio frequentadores ainda com vida e, por fim, a aglomeração de corpos cobertos por lonas".

Nos sites de redes sociais, a mobilização dos usuários gerou uma rede de solidariedade que prosseguiu nos dias subsequentes à tragédia - com o compartilhamento de uma diversidade de informações que atualizavam a situação e convocavam formas de ajuda voluntária. Essa articulação em rede teria sequência na mobilização das pessoas em torno de manifestações públicas de luto, homenagem às vítimas e luta por justiça.

A repercussão midiática da tragédia suscitou inúmeras análises sobre a cobertura do evento. Pesquisadores de diferentes áreas se voltaram à análise do caso, resultando na publicação de centenas de artigos e algumas teses e dissertações. No campo da Comunicação, os estudos detiveram-se, sobretudo, na cobertura jornalística do acontecimento e nas articulações via redes digitais (JÁCOMO, 2013; SOUSA, 2013; SILVA, 2014; BOLDRIN, 2015; KEGLER, 2016; MOTTA, 2016; SILVEIRA, 2018).

Ao analisar a cobertura feita pelo jornal Zero Hora, Marocco (2013, p. 210) identificou cinco movimentos que organizaram o conjunto de ações da prática jornalística:

1) resgate dos corpos, identificação sociocultural dos mortos e desespero dos parentes vivos, levantamento de suspeitas sobre a responsabilidade criminal, editorialização retórica da culpa; dimensionamento e regionalização da tragédia; 2) dramas dos sobreviventes, jornada dos heróis, primeiras evidências de culpabilidade, nacionalização e internacionalização da tragédia, ações de solidariedade, acompanhamento da evolução dos feridos, recontagem dos mortos; 3) a dor dos jornalistas, autorreferencialidade; 4) contabilidade dos mortos e drama dos sobreviventes; 5) repercussões finais com a mudança do estatuto do acontecimento: de tragédia a crime.

Esses movimentos sinalizam um ordenamento composto pela articulação de duas camadas: uma ampla, referente a práticas já consolidadas no jornalismo, inscritas no cânone interpretativo e convocadas quando ocorre uma situação-limite; e outra mais específica, que se forma a partir daquilo que o próprio acontecimento em questão reclama, de suas singularidades, desdobramentos narrativos, circuitos informativos formados, agentes e sua aparição na cena pública. 
A cobertura do caso e as análises sobre ela demonstram os constrangimentos, as dificuldades e a necessidade de se narrar o trágico. Essa necessidade de contar a experiência permanece e se atualiza. No aniversário de cinco anos da tragédia, a jornalista Daniela Arbex lançou o livro Todo dia a mesma noite: a história não contada da Boate Kiss. O que não se sabe sobre um acontecimento que teve tanta repercussão midiática? É no testemunho dos sobreviventes e de familiares de vítimas, que vivenciaram as intermináveis horas daquele dia 27, que a repórter busca uma possibilidade de narrar o acontecimento e de mostrar como todos, ainda hoje, sobrevivem cotidianamente à tragédia.

A partir da leitura do livro e de cinco entrevistas concedidas por Arbex a diferentes veículos de mídia, este texto discute as possibilidades de transgressão ao regime de práticas jornalísticas consolidadas quando o acontecimento se refere a experiências de sofrimento. Compreendemos que existem procedimentos regulares que controlam e normatizam as práticas (FOUCAULT, 2005). No jornalismo, esses procedimentos funcionam no ordenamento de um conjunto de práticas consolidadas com o tempo. Há, no entanto, espaços nos quais é possível observar um processo de autonomização dos sujeitos jornalistas, que elaboram métodos próprios e criativos, muitas vezes na contramão dos procedimentos padrões. Um desses espaços é o "livro de repórter" (MAROCCO, 2011, 2018; ZAMIN, 2011).

O objetivo deste exercício reflexivo, portanto, é perceber as aproximações do trabalho empreendido por Daniela Arbex à noção de "livro de repórter", sinalizando a potencialidade crítica dessa escrita como processo transgressivo de reconhecimento do presente (MAROCCO, 2008). Nesse sentido, utilizamos como chave de leitura a noção de "evento crítico" (DAS, 1996), a fim de compreender as particularidades dessa crítica quando o sofrimento é um operador significante na construção narrativa do acontecimento.

\section{Transgressão em "livros de repórter"}

Na história do jornalismo, convencionou-se nomear de livro-reportagem "o veículo de comunicação impressa não-periódico que apresenta reportagens em grau de amplitude superior ao tratamento costumeiro nos meios de comunicação jornalística periódicos" (LIMA, 2004, p. 26). À noção de livro-reportagem, inscrevem-se inúmeras obras - muitas canônicas no campo - e tende-se, ainda que de modo não consensual, a enquadrá-las como jornalismo literário (ou jornalismo narrativo, novo jornalismo, romance reportagem, dentre outras denominações). Zamin (2011, p. 393) considera que "compreender estes livros como uma possibilidade editorial ou como um expediente utilizado por alguns jornalistas é redutivo, assim como categorizá-los simplesmente como literários". Para a autora, tais perspectivas "eliminam a possibilidade de aprofundar a compreensão do jornalismo a partir destas obras" (Ibidem).

Se as análises que trabalham com a noção de livro-reportagem se ancoram no deslocamento jornalismo-literatura, Marocco (2011) propõe estudar os livros escritos por 
jornalistas a partir de um deslocamento jornalismo-jornalismo (ZAMIN, 2011). Para tanto, elabora o conceito de livro de repórter:

Trata-se de um tipo de texto que se ocupa do jornalismo, para dele elaborar outro texto que oferece o desvendamento de certos processos jornalísticos, ou a crítica dos mesmos, em operações de produção de sentidos, em que o jornalista, naturalmente, fará um exercício de interpretação criativa do que é considerado jornalismo (MAROCCO, 2011, p. 121).

A autora compreende o livro de repórter como atualização do "comentário", um dos procedimentos internos de controle discursivo (FOUCAULT, 1996). O livro de repórter é a materialização do comentário sobre práticas, "que não tem lugar no jornalismo senão ali, onde os repórteres encontram tempo para proceder a uma análise epistemológica reflexiva" (MAROCCO, 2015, p. 84).

Nesse sentido, o livro de repórter pode ser pensado como um espaço de tensão entre os controles discursivos do jornalismo e a resistência com que os repórteres se opõem a eles. É no estabelecimento dessa crítica ao jornalismo que Marocco (2018, p. 67) situa dois limiares: uma "hermenêutica jornalística" e uma "ação de criação em relação ao jornalismo". Em ambos está implicado um deslocamento da disciplina jornalística a uma autoralidade individual - "repórter-autor". Nesse processo de criação dentro do jornalismo, o repórter volta seu exercício de crítica como "reconhecimento do presente" (MAROCCO, 2018).

A noção aqui empregada de um jornalismo como reconhecimento do presente é oriunda de reflexão feita por Foucault (2008) em seu texto "As reportagens de ideias". Como explicam Marocco, Zamin e Boff (2012, p. 93), Kant inaugura um modo filosófico de reconhecimento e de crítica a certo elemento do presente, ao discorrer sobre a "repercussão que teve no espírito dos homens que acompanhavam de longe [a Revolução Francesa], sem interesse, o desenvolvimento da trama". A atitude crítica de Kant de reconhecimento do presente é deslocada da Filosofia para o Jornalismo por Foucault (2008), quando ele vai ao Irã e, de lá, escreve reportagens sobre o que conhecemos como "Revolução Islâmica".

Publicado em 1978, no Corriere della Sera, o artigo de Foucault insurge como proposta de que o jornalismo trabalhe com o presente não de um lugar hegemônico e operacional, mas via outra lógica que reformule a concepção da fonte jornalística e o próprio processo interpretativo do jornalista-intelectual sobre o acontecimento que testemunha. Foucault "criticou o jornalismo e fez dele espaço de transgressão ao dedicar-se ao exercício da reportagem" (ZAMIN e SCHWAAB, 2017, p. 165). O gesto transgressivo é entendido em sua potência enquanto indicativo de diferença. O filósofo se vale das práticas e processos de produção jornalística, mas subverte o regime das normas que conformam o fazer jornalístico. A reportagem é vista, assim, como espaço potente para a transgressão. 


\begin{abstract}
Não há reportagem, em nosso entendimento, que não se torne um fragmento de jornalismo, um pedaço que só existe porque existe em torno dele, antes e depois dele, algo como a continuidade do jornalismo, mas que, em suas margens e/ou com ele, pode formar duas figuras estranhas. Uma delas é a figura da transgressão, do modo transgressivo de reconhecimento da época em que se vive, na palavra ou na imagem transgressiva (MAROCCO, 2008, p. 34).
\end{abstract}

Os livros de repórter são "assumidos como instância de acolhimento de críticas ao jornalismo e de transgressão" (ZAMIN e SCHWAAB, 2017, p. 164), contrapondo-se às normatizações do regime das práticas. O gesto transgressivo de reconhecimento do presente torna-se perceptível na própria narrativa, a partir daquilo que o repórter oferta, por meio de códigos outros incorporados à reportagem.

\title{
Todo dia a mesma noite
}

Investigar histórias tramadas sob o signo do sofrimento é marca da produção jornalística de Daniela Arbex - também autora de Holocausto Brasileiro (2013) e Cova 312 (2016). Em 16 capítulos, Todo dia a mesma noite conta, de uma perspectiva até então pouco explorada, a história da "Tragédia de Santa Maria", como ficou conhecido o incêndio ocorrido, em janeiro de 2013, na Boate Kiss, em Santa Maria (RS). O trabalho é fruto de um exaustivo processo de apuração, que contou com centenas de horas de entrevistas com sobreviventes, familiares de vítimas, socorristas e profissionais da saúde.

A narrativa inicia com a calmaria no Serviço de Atendimento Móvel de Urgência, que tinha atendido apenas uma ocorrência naquela semana. De modo sensível, Arbex nos transporta para aquele sábado. Acompanhamos as personagens em suas rotinas: as vítimas antes de ingressarem na festa, os socorristas antes de receberem o alarme, as famílias antes do choque da notícia. Temos acesso a detalhes sobre o incêndio, sobre os procedimentos da equipe de resgate, sobre a busca dos familiares por seus filhos nos hospitais e no ginásio para onde foram levados os corpos. Arbex não limita sua narrativa ao que ocorrera naquele dia; ela questiona sobre os dias seguintes, procura identificar as causas e explorar as consequências dos descuidos banalizados por agentes públicos e empresários. Frente a uma comunidade solapada pela catástrofe, a repórter questiona de que modo essas pessoas continuam, cotidianamente, sobrevivendo à tragédia.

Em entrevistas, Arbex conta que foi praticamente convocada para contar a história da Kiss quando um colega de trabalho Ihe contou que havia conhecido uma enfermeira de Santa Maria e que, depois da conversa, estava convencido de que ela deveria escrever sobre a tragédia. A repórter contrapôs: "Mas todo mundo já contou essa história" (ARBEX, 2018b). Ele insistiu tanto que ela começou a pesquisar e, no primeiro contato com uma mãe que havia perdido o filho no incêndio, teve como resposta: "Que bom. Nós precisamos ser ouvidos" (ARBEX, 2018b). Começava ali o processo de apuração. Logo veio a primeira das cinco viagens que faria a Santa Maria. 
Mesmo sabendo que o incêndio na Boate Kiss teve grande visibilidade midiática, Arbex não se orientou pela ideia de que não haveria mais o que ser contado sobre o caso. Ela afirmou que existe uma "falsa ideia de que as histórias se esgotam, porque sempre existem coisas por serem ditas" (ARBEX, 2018c). A repórter contraria o regime de normas que norteia o jornalismo pela atualidade do fato, pela cobertura simultânea, e se coloca em outro espaço: "Minha palavra é sempre resistência" (ARBEX, 2018c).

Ao refletir sobre seu trabalho como repórter, Arbex olha em retrospecto e inscreve Todo dia... na sua biografia, enquanto parte de uma obra maior e que caracteriza o próprio processo de autonomização em relação à disciplina jornalística:

Eu precisei passar pelo Holocausto [Brasileiro] e pelo Cova [312] para estar preparada para empreender esse voo solo. Solo no sentido de que eu ia estar deslocada das minhas origens. [Todo dia... é um] livro do não esquecimento, para fazer lembrar, discutir o Brasil de hoje. [...] Eles se cruzam nesse sentido, nessa luta pela construção da memória, pra que a gente aprenda um pouco com todos esses eventos que nos marcaram (ARBEX, 2018b).

A Kiss entrou na minha vida como um dos maiores desafios da minha carreira. [...] Com o tempo, percebi que os temas tinham muito em comum, porque, em todos os casos, a construção da memória era necessária (ARBEX, 2018d).

A repórter estabelece conexões entre um trabalho e outro, o que aponta uma característica de autoria - a existência de um tema que perpassa sua obra e que, pelos seus textos, é possível ter acesso. Se antes discutia fatos ocorridos em décadas passadas, em Todo dia... ela aborda um acontecimento recente, mas já marcado pela necessidade de resgate de sua memória.

Observar como a repórter interpreta suas práticas ajuda a compreender os modos como a identidade profissional é forjada. Além disso, dá-se a ver um conjunto de saberes, marcados pelo gesto transgressivo, que se contrapõe ao regime das práticas jornalísticas e passa a orientar o trabalho da repórter.

Todos os livros me causaram impactos profundos, mas nada mexeu tanto comigo quanto o mergulho no caso Kiss. Fiquei tão abalada que passei a ter medo de perder meu filho. Isso afetou muito a minha rotina familiar. Pela primeira vez, precisei procurar ajuda especializada (ARBEX, 2018d) $)^{2}$

Eu chorei em todas as entrevistas, durante, depois, e enquanto escrevia. Foi muito duro ouvir tudo aquilo, compartilhar o tamanho da dor dessas pessoas (ARBEX, 2018e).

2 Os grifos nas citações são todos nossos, para destacar elementos importantes para a análise. 
Arbex revela como o processo de produção da reportagem também a abalou. Vemos uma prática que é orientada pela subjetividade, situada a partir das vivências da repórter, de suas concepções de mundo e da forma como se coloca frente às histórias que precisa narrar. Tal compreensão aproxima-se da noção de "prática corporificada" - quando "o corpo e as emoções são discursivisados como parte da racionalidade no processo de cognição para a leitura e narração da realidade, e dão indicativos de ser um dos modos de deslocamento da objetivação jornalística" (SILVA e MAROCCO, 2018, p. 41). Se a subjetividade é interditada pelas prescrições de um jornalismo tecnicista que se pretende isento, imparcial e objetivo, no trabalho de jornalistas como Arbex, a subjetividade se estabelece como orientação e também como resistência aos controles discursivos.

Guiar seu trabalho pela ação subjetiva não significa abrir mão de preceitos básicos do jornalismo sobre a apuração dos fatos. Pelo contrário, a abertura a uma postura mais humanizada dimensiona a preocupação de jornalistas em relação à coleta de informações e entrevistas. Arbex afirma que, após ter escrito o livro, leu para seus interlocutores os capítulos, a fim de identificar e eliminar possíveis erros.

\begin{abstract}
A leitura é por tudo isso: pela necessidade de checagem, esse rigor tem que ser exaustivo. Você tem que checar, checar e checar. Eu liguei várias vezes para perguntar a mesma coisa depois que o livro já estava pronto. As pessoas me falavam: "Daniela, você já me perguntou isso". E eu respondia: "mas eu continuo com dúvida" (ARBEX, 2018f).
\end{abstract}

Arbex se refere à precisão do que se narra, porque narrar a vida do outro implica constante vigilância que não diz respeito apenas ao que se conta, mas também a como se conta. Não se busca a verdade, porque uma história possui diferentes perspectivas e múltiplas entradas; as dúvidas nunca se esgotam.

Quando você permite que o outro habite em você e se deixa habitar pela dor do outro, é possível enxergar o tamanho desse sofrimento. Você consegue sentir um pouco o que o outro está sentindo. [...] A humanização é o grande caminho do jornalismo. Ao se colocar no lugar do outro, isso provoca mudança. É algo que transforma o olhar e o sentimento das pessoas. Tocar o outro é um grande caminho, reforçar esse papel do jornalismo como instrumento de transformação social (ARBEX, 2018f).

Notamos que o trabalho de Arbex é marcado pela ação subjetiva e pela resistência. Ao refletir sobre sua prática, ela oferta outra compreensão sobre o jornalismo, que foge às normatizações do sistema canônico. Em determinado momento, assevera a função do olhar, da escuta e da postura humanizada como caminho possível para um jornalismo mais afeito à alteridade. Sinalizar esse caminho nada tem a ver com renegar os fundamentos epistemológicos do campo - antes disso, é um movimento que abre e amplia essas bases, 
possibilitando uma prática transgressiva e que se consolida à margem dos controles, da objetivação e da racionalidade tecnicista.

Nesse sentido, a repórter se lança na difícil tarefa de narrar um acontecimento trágico. É no processo de habitar o outro e deixar-se habitar pelo outro que se encontra a forma de produzir uma reportagem orientada pela alteridade e que tem nos testemunhos o centro de sua construção. É sobre esse processo de escrita que discutimos a seguir.

\section{A partilha da dor}

Eu só consegui entender o tamanho desse trauma quando eu cheguei lá, porque eu percebi a magnitude da devastação. Essa dor que a tragédia provocou é uma dor que continua em movimento. Eu digo que nunca cheguei em Santa Maria e encontrei as famílias da mesma forma que eu deixei (ARBEX, 2018f).

Narrar a dor do outro é um problema posto ao jornalismo. Isso porque, como lembra Ricoeur (1992, p. 8), "o sofrimento interpela", rompe o fio narrativo, ao estabelecer uma lacuna entre querer dizer e a incapacidade para o dizer. Esse sofrimento não apenas interpela aqueles expostos à tragédia no momento de sua eclosão, mas a todos que vivem essa fratura, inclusive a própria repórter. Interpelada pelo sofrimento, Arbex se vê obrigada a reorientar os modos como habita e narra o mundo.

Em seus trabalhos, Das $(1996,2007)$ busca entender o que as pessoas fazem em meio à devastação deixada por aquilo que nomeia de "evento crítico"3. Eventos críticos são acontecimentos que possuem vários níveis e dimensões, caracterizados pela brutalidade pela qual não apenas afetam a vida daqueles que sofreram o evento, mas também deflagram transformações nos indivíduos e nas instituições que são historicamente ou imaginariamente atingidos por suas contingências e desdobramentos.

Jovens morriam na frente de todos, uma cena insuportável até mesmo para quem fora treinado para enfrentar situações-limite (ARBEX, 2018a, p. 20).

Embora não fizesse a menor ideia do que teria acontecido no interior da casa noturna, [o médico socorrista] Dornelles tinha certeza de que aquela madrugada de domingo, marcada pelo barulho ensurdecedor das sirenes, mudaria para sempre a sua vida, a história da cidade e, quem sabe, a do país (ARBEX, 2018a, p. 21).

3 Ainda que partam de orientações epistêmicas distintas, os conceitos de "evento crítico" (DAS, 1996) e "acontecimento" - na perspectiva de Quéré (2005), especialmente - guardam similaridades. Ambos buscam dar conta de ocorrências que provocam fissuras na realidade, instauram descontinuidades que convocam formas de atuação e explicação, articuladas à experiência, aos modos de afetação. As formas como nos apropriamos dos acontecimentos também os configuram e é nesse processo de (re)configuração e afetação que as pessoas constroem formas de "habitar o mundo", nos termos de Das (2007). A extensão e o objetivo deste texto impedem uma exploração mais aprofundada das relações entre esses conceitos. Mesmo sendo "acontecimento" um termo mais corrente em nossa área, opto por utilizar "evento crítico" (e não "acontecimento crítico", outra tradução possível), respeitando assim o modo como a pesquisa antropológica brasileira tem traduzido o termo e se referido ao conceito. 
A capitã da brigada caminhou pela Kiss atordoada não só pelo que viu, mas com o barulho dos celulares das vítimas. [...] Aquela sinfonia da tragédia era tão insuportável quanto a cena que Liliane presenciava. Como lidar com um evento dessa proporção? (ARBEX, 2018a, p. 34-35).

Em silêncio, o trabalho [de retirada dos corpos] foi reiniciado no interior da boate. Lá fora, porém, a dor iria acordar o país (ARBEX, 2018a, p. 36).

Como se tratava de uma tragédia humana sem precedentes na história recente do país, o emergencista intuía que as consequências seriam sentidas em ondas. As próximas chegariam tão fortes que provocariam devastação semelhante a um tsunami. Ninguém em Santa Maria sairia ileso (ARBEX, 2018a, p. 72).

Nos excertos acima, notamos o movimento que a autora faz para dar ao leitor a dimensão da tragédia a partir dos relatos da equipe de socorristas. Os primeiros capítulos do livro reconstroem os momentos de horror daquela madrugada. A identificação do evento crítico é feita pela repórter através das impressões das pessoas, que na situação ainda não dimensionavam o acontecimento, mas intuíam - pelas cenas insuportáveis que presenciavam - que suas consequências abalariam a todos. Nesse movimento, Arbex faz o reconhecimento do evento que relata, examinando seu engendramento.

Outra característica do evento crítico é romper com a cotidianidade e instaurar quadros que desestabilizam as referências que as pessoas possuem. Conferindo inteligibilidade ao evento crítico, a repórter busca um ordenamento que se dá, muitas vezes, recorrendo a imagens já cristalizadas em nosso imaginário sobre o sofrimento:

Próximo a um poste de luz, conseguiu se enxergar pela primeira vez, percebendo que a pele de seu braço estava presa apenas pelo pulso. Por um instante, pareceu a pequena Kim Puch, vítima da Guerra do Vietnã, cujo povoado fora atingido 41 anos antes por um bombardeio. Só que o corpo de Gustavo estava sendo consumido não por queimaduras provocadas por bombas de napalm, conforme mostra a famosa foto de Kim, mas pela onda de calor a que fora exposto dentro da boate minutos antes (ARBEX, 2018a, p. 25-26).

É também notável o esforço da repórter em romper com a relação produtiva entre jornalista e fonte, que o regime de normas preconiza. Os entrevistados são centrais na escrita da reportagem. Seus testemunhos dão a conhecer os momentos vivenciados naquela madrugada e nas horas que se seguiram ao incêndio. Na leitura do texto, percebemos o valor desses testemunhos - já que a repórter dificilmente teria acesso a maior parte do que ali está narrado se não fosse pelo que contam as testemunhas. No trabalho de narrar o outro, Daniela opta por não aparecer no texto - abre mão de marcadores autorreferenciais, não narra em primeira pessoa -, utiliza muitos diálogos - o que demonstra um exaustivo processo de apuração - e busca mostrar as personagens não 
de modo heroico ou sobre-humano - pelo contrário, é diante do torpor causado pela tragédia que ela busca a humanidade.

Diante da pilha de corpos, o sargento [do Corpo de Bombeiros] sentiu as forças de seus braços esvaírem. [...] Nenhum treinamento o havia preparado para lidar com a dor que sentiu no momento em que se viu tomado pelo mais humano dos sentimentos: a compaixão. - Nós não salvamos ninguém - repetia, em choque (ARBEX, 2018a, p. 30).

Conforme Das (1996), o evento crítico se une e se desdobra na vida cotidiana, em contínuos processos na tentativa de reconstruir suas vidas. As pessoas, afetadas pelo evento crítico e vivendo as rupturas por ele determinadas, não se refazem pelo esquecimento dessa experiência, de seus sentimentos ou de seu passado; elas constroem imersas na dor, na convivência com a experiência do sofrimento.

É esse trabalho de convivência com a dor que Arbex identifica quando percebe que a tragédia "provocou uma dor que continua em movimento". De diferentes formas, as pessoas que sofreram a fratura social se veem impelidas a reconstruir seus mundos a partir do evento crítico. À repórter é destinado o trabalho de descrever e interpretar tais movimentos. É pelo texto-reportagem que acessamos as maneiras que os sobreviventes encontraram de "habitar o mundo" (DAS, 2007).

Como ressignificar toda uma existência? Exausto, Paulo parecia ter ganhado vinte anos em poucas horas. Estava alquebrado, dividido ao meio. Não sabia como se juntar. Desejava fugir dali, buscar o filho vivo em sua caixa de memórias (ARBEX, 2018a, p. 133).

Naquela segunda-feira, enquanto Silvinho era enterrado, os vizinhos do sítio de sua família realizavam o mutirão para dar andamento ao que o jovem havia iniciado: o cultivo da lavoura para a colheita do arroz que havia plantado. Seguiram o projeto definido anteriormente pelo rapaz. Com trator e pá, eles entraram na plantação. Não deixariam o sonho dele morrer também (ARBEX, 2018a, p. 159).

Todo dia a mesma noite pode ser lido como um trabalho que possibilita a leitura de um evento crítico e de seus desdobramentos - identificados a partir das maneiras como a autora relata as formas que as testemunhas habitam o mundo na situação do trauma. Nesse movimento, a repórter oferta aos leitores uma interpretação sobre o acontecimento narrado.

De alguma forma, todos são sobreviventes dessa tragédia, porque as pessoas que não morreram dentro da boate, que ficaram, foram profundamente, diretamente, afetadas por esse evento. A Kiss provocou uma devastação humana. Da mesma forma que a fumaça seguiu agindo no organismo, essa devastação seguiu agindo nas pessoas (ARBEX, 2018b). 
[A dor] continua agindo. Não é uma dor que provocou aquela ferida e fechou. A ferida continua abrindo. É movimento porque você não consegue pedir superação. Ninguém supera a morte de um filho. Exigir superação é uma total falta de empatia com a dor do outro. Se hoje eu for lá, talvez as pessoas estejam [bem]. Mas eu posso voltar daqui um tempo e aquela pessoa, que estava cheia de projetos, cai na cama, em depressão, como foi a caso da Carina (mãe de uma vítima). Eu cheguei para ler para ela (o capítulo do livro) e ela estava deitada, em uma depressão fortíssima. A dor em movimento também tem muito a ver com a falta de justiça (ARBEX, 2018f).

Se o evento crítico deixou o mundo devastado, é necessário pegar os pedaços e seguir em frente. Seguir em frente não significa superar a dor - algo impossível, como Arbex afirma - mas construir em cima da dor. Das (2007) também concorda que a dor não se supera, que existe um trabalho de construção que se realiza em função do trabalho do tempo. Não existe, portanto, a ideia de que tudo está (ou pode ficar) resolvido. Nesse sentido, Arbex é perspicaz ao perceber que a devastação segue agindo nas pessoas, às vezes de formas pouco acessíveis, tal qual a fumaça seguia agindo no organismo das vítimas que conseguiram sair do incêndio e que vieram a morrer horas depois, em decorrência de sua ação.

\section{Algumas considerações}

Quando Foucault realiza sua reportagem no Irã, ele parte do questionamento: "O que está acontecendo com nosso presente que não chega até nós?" (MAROCCO, 2008, p. 44). Sua interrogação é potente e ainda hoje reverbera quando pensamos no regime de práticas que orientam e normatizam o fazer jornalístico. Ainda que o jornalismo seja guiado por critérios e normas que se balizam pela presentificação do acontecimento o aqui e o agora do que é estipulado como relevante -, o filósofo nos faz refletir sobre os acontecimentos que se escrevem nas marginálias da História e, por conseguinte, do trabalho do jornalista na narração desses acontecimentos.

A indagação de Foucault é basilar na concepção do livro de repórter enquanto outro espaço de crítica das práticas jornalísticas. Há nele espaço para a elaboração de uma hermenêutica do jornalismo e de uma ação criativa por parte do repórter. Nesse sentido, o jornalista se inscreve no mundo enquanto observador da realidade que reporta o presente por meio de um processo de reconhecimento - balizado pelo olhar atento, pela escuta sensível, pela afeição à alteridade, pela potência afetiva da narração, pelas histórias ordinárias, pelo que contam os rastros.

Por essa abordagem, consideramos Todo dia a mesma noite um livro de repórter que tem como orientação reconhecer o presente, pela presença da dor, e estabelecer práticas que se distanciam da norma. São os gestos transgressivos da repórter que a aproximam 
à noção de autora. Sua obra torna-se espaço de discussão do jornalismo e também dos temas que nele são inscritos. No caso de Todo dia..., o sofrimento torna-se operador central na constituição narrativa da trama ao interpelar a repórter, fazendo-a repensar sua atuação deontológica no mundo.

Para compreender como se dá a transgressão no trabalho de Daniela Arbex, realizamos uma leitura analítica de seu livro e também de suas entrevistas - entendidas aqui como espaços outros em que é possível identificar o exercício crítico do repórter em relação às práticas. Ainda que a tragédia tenha acontecido há cinco anos e que Arbex não a tenha vivenciado de perto, ela realiza um reconhecimento do presente no sentido de elaborar um exercício hermenêutico que se ocupa da constituição do evento crítico e do modo como a tragédia ainda reverbera na vida de todos os que foram afetados por ela. A repórter não se coloca no lugar de quem sofre, mas ao lado. Potencializa ao máximo os testemunhos e tece, a partir deles, sua narrativa. Do evento crítico restam as migalhas, os escombros, os fragmentos. É seguindo esses rastros que Arbex ajuda a compor a narrativa de uma dor partilhada.

Marlon Santa Maria Dias é doutorando em Ciências da Comunicação na Universidade do Vale do Rio dos Sinos, com bolsa CAPES/PROEX. É mestre em Comunicação e Bacharel em Comunicação Social, habilitação em Jornalismo, pela Universidade Federal de Santa Maria.

marlon.smdias@gmail.com

\section{Referências}

ARBEX, D. Todo dia a mesma noite: a história não contada da Boate Kiss. Rio de Janeiro: Intrínseca, 2018a.

Daniela Arbex conta sobre novo livro, "Todo dia a mesma noite". [Entrevista disponibilizada em 21 de janeiro de 2018]. Tribuna de Minas, YouTube. 2018b. Disponível em: https://goo.gl/GRtyPo. Acesso em: 10 ago. 2018.

. Escritora resgata histórias esquecidas para a construção da justiça. [Entrevista disponibilizada em 15 de abril de 2018]. EBC Rádio. 2018c. Disponível em: https://goo.gl/h3Hmxp. Acesso em: 10 ago. 2018.

"Esquecer seria negar a história", diz autora de livro sobre a Kiss. [Entrevista disponibilizada em 19 de janeiro de 2018]. GaúchaZH. 2018d. Disponível em: https://goo.gl/73up5j. Acesso em: 10 ago. 2018.

. Escritora premiada, Daniela Arbex lança o livro 'Todo dia a mesma noite', sobre a tragédia da Kiss. [Entrevista disponibilizada em 25 de janeiro de 2018]. G1. 2018e. Disponível em: https:// goo.gl/1 Hm5mn. Acesso em: 10 ago. 2018. 
"Falta de justiça provoca dor semelhante à da perda", diz autora de livro sobre boate Kiss. [Entrevista disponibilizada em 2 de abril de 2018]. Diário Catarinense. 2018f. Disponível em: https:// goo.gl/fCHLU8. Acesso em: 10 ago. 2018.

BOLDRIN, M. M. A imaginação melodramática no Jornal Nacional. 2015. 118 f. Dissertação (Mestrado em Comunicação), Universidade Federal de Goiás, Goiânia, GO, 2015.

DAS, V. Critical Events: An Anthropological Perspective on Contemporary India. New Delhi: Oxford University Press, 1996.

Life and Words: violence and the descent into the ordinary. University of California Press, London: England, 2007.

FOUCAULT, M. A ordem do discurso. São Paulo: Edições Loyola, 1996.

A arqueologia do saber. Rio de Janeiro: Forense Universitária, 2005.

As reportagens de ideias. In: BERGER, C.; MAROCCO, B. Ilha do Presídio: uma reportagem de ideias. Porto Alegre: Libretos, 2008. p. 49-51.

JÁCOMO, T. C. Jornalismo e redes sociais: novas práticas e tendências a partir da cobertura do portal "G1.com" sobre o incêndio da Boate Kiss em Santa Maria, Rio Grande do Sul, Brasil. 97 f. Dissertação (Mestrado em Comunicação e Jornalismo), Universidade de Coimbra, Portugal, 2013.

KEGLER, B. Redes de comunicação pública, visibilidade e permanência do acontecimento público Tragédia Kiss (Santa Maria, Brasil, 2013). 2016. 231 f. Tese (Doutorado em Comunicação e Informação), Universidade Federal do Rio Grande do Sul, Porto Alegre, RS, 2016.

LIMA, E. P. Páginas ampliadas: o livro-reportagem como extensão do jornalismo e da literatura. Campinas: Ed. da UNICAMP, 2004.

MAROCCO, B. Reportagem de transgressão, um giro no tratamento da fonte jornalística. In: BERGER, C.; MAROCCO, B. Ilha do Presídio: uma reportagem de ideias. Porto Alegre: Libretos, 2008, p. 33-47.

. Os "livros de repórter", o "comentário" e as práticas jornalísticas. Revista Contracampo, n. 22, fev. 2011, p. 116-129.

O acontecimento em curso, o jornalismo e os saberes subjugados. In: VOGEL, D.; MEDITSCH, E.; SILVA, G. (Org.) Jornalismo e acontecimento: tramas conceituais. V. 4. Florianópolis: Insular, 2013. Os procedimentos de controle e a resistência na prática jornalística. Galaxia, n. 30, p. 73 85, dez. 2015.

. Giro autoral no "livro de repórter". Galaxia, n. 37, p. 66-79, jan-abr. 2018.

; ZAMIN, A.; BOFF, F. Os "grandes acontecimentos" e o reconhecimento do presente. Verso e Reverso, v. 26, n. 62, p. 92-102, maio-ago. 2012.

MOTTA, J. Os testemunhos na cobertura ao vivo do incêndio da Boate Kiss. 2016. 163 f. Dissertação (Mestrado em Comunicação), Universidade Federal de Santa Maria, Santa Maria, RS, 2016.

QUÉRÉ, L. Entre facto e sentido: a dualidade do acontecimento. Trajectos. Revista de Comunicação, Cultura e Educação. Lisboa, n. 6, p. 59-75, 2005.

RICOEUR, P. O sofrimento não é a dor. Psychiatrie Française, n. especial, p. 1-8, jun. 1992. Disponível em: http://www.uc.pt/fluc/uidief/textos_ricoeur/o_sofrimento_nao_e_a_dor. Acesso em: 10 ago. 2018.

SILVA, C. M. Mobilização Social no Facebook: conectando solidariedade e justiça no caso da Boate Kiss. 2014. 155 f. Dissertação (Mestrado em Comunicação), Universidade Federal de Santa Maria, Santa Maria, RS, 2014. 
SILVA, M. V.; MAROCCO, B. O feminino no "livro de repórter": uma mirada epistemológica de gênero sobre as práticas jornalísticas. Brazilian Journalism Research, v. 14, n. 1, abr. 2018.

SILVEIRA, A. C. M. (Org.) Midiatização da tragédia de Santa Maria. A catástrofe biopolítica. Volume I. 2. ed. Santa Maria: FACOS-UFSM, 2018.

SOUSA, M. C. E. A dinâmica da notícia nas redes sociais na internet. 2013. 285 f. Dissertação (Mestrado em Jornalismo), Universidade Federal de Santa Catarina, Florianópolis, SC, 2013.

ZAMIN, A. "Livros de repórter", saberes de entremeio: relatos jornalísticos sobre a cobertura de conflitos. Estudos em Jornalismo e Mídia, v. 8, p. 389-405, 2011.

.; SCHWAAB, R. Um acidente no relato, um atentado na edição; e outras reflexões acerca das práticas jornalísticas. Galaxia, n. 34, p. 163-174, jan.-abr. 2017. 